\title{
Integrated response and transit time distributions of watersheds by combining hydrograph separation and long-term transit time modeling
}

\author{
M. C. Roa-García ${ }^{1,3}$ and M. Weiler ${ }^{2}$ \\ ${ }^{1}$ Land and Food Systems, University of British Columbia, 2357 Main Mall, Vancouver, B.C., V6T 1Z4 Canada \\ ${ }^{2}$ Institute of Hydrology, University of Freiburg, Fahnenbergplatz, 79098 Freiburg, Germany \\ ${ }^{3}$ Fundación Evaristo García, A.A. 4443, Cali, Colombia
}

Received: 6 December 2009 - Published in Hydrol. Earth Syst. Sci. Discuss.: 6 January 2010

Revised: 25 May 2010 - Accepted: 18 July 2010 - Published: 13 August 2010

\begin{abstract}
We present a new modeling approach analyzing and predicting the Transit Time Distribution (TTD) and the Response Time Distribution (RTD) from hourly to annual time scales as two distinct hydrological processes. The model integrates Isotope Hydrograph Separation (IHS) and the Instantaneous Unit Hydrograph (IUH) approach as a tool to provide a more realistic description of transit and response time of water in catchments. Individual event simulations and parameterizations were combined with long-term baseflow simulation and parameterizations; this provides a comprehensive picture of the catchment response for a long time span for the hydraulic and isotopic processes. The proposed method was tested in three Andean headwater catchments to compare the effects of land use on hydrological response and solute transport. Results show that the characteristics of events and antecedent conditions have a significant influence on TTD and RTD, but in general the RTD of the grassland dominated catchment is concentrated in the shorter time spans and has a higher cumulative TTD, while the forest dominated catchment has a relatively higher response distribution and lower cumulative TTD. The catchment where wetlands concentrate shows a flashier response, but wetlands also appear to prolong transit time.
\end{abstract}

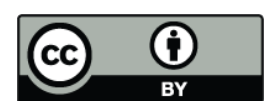

Correspondence to: M. C. Roa-García (croa09@gmail.com)

\section{Introduction}

Water management with the aim to sustain catchment ecological services requires an understanding of the hydrologic cycle. Comparative analysis of catchment behavior allows observing the effects of human activities on the amount and rate of water flows, the effects of land use change on water quantity and quality, the persistence of soluble contaminants in catchments, and the vulnerability of ecosystems to be impacted by climate change. Comparing flows, residence time and transit time of water from catchments with similar size, topography and soil type, enables us to understand the influence that particular catchment components and processes have on catchment response to precipitation and to dry periods.

Stable water isotopes have been used in hydrology for two purposes: (1) to identify the temporal variations of water sources for baseflow and for individual storms; and (2) to identify the source of runoff during an event, e.g. whether it comes from rain or snowmelt (event water) or from water stored in the watershed prior to the event (groundwater, soil water, lakes etc.) (Vitvar et al., 2005). This knowledge has been used to understand the interactions between precipitation, runoff pathways and runoff generation processes, and as a proxy for the capacity of a catchment to store water and chemicals and regulate its flow (Soulsby et al., 2009).

The models used to analyze isotope data in hydrology have been developed based on earlier hydrological tools focused on graphical separations of stream flow components (e.g. quick and slow flows) and unit hydrograph models to predict peak discharge and to extract lumped physical characteristics

Published by Copernicus Publications on behalf of the European Geosciences Union. 
of drainage basins (Sherman, 1932; Clark, 1945; Barnes, 1940; Hewlett and Hibbert, 1967). Later, tracers have been used in a more objective way to separate the storm hydrograph. Stable isotope hydrograph separations (IHS) (Pinder and Jones, 1969; Sklash et al., 1976) and conservative geo-chemical tracing (Hooper and Shoemaker, 1986) have been developed into common tools in watershed hydrology (Kendall and McDonnell, 1998). These tracer-based separation approaches have the advantage of providing more process-based information about temporal and geographic sources of runoff.

Lumped transport models to estimate the transit time of water in catchments or other hydrological systems (groundwater, unsaturated zone) have been developed in parallel to predict the transit time distribution (TTD) and mean transit time (MTT) of a system (Maloszewski and Zuber, 1982). These models have been used mostly under baseflow conditions in catchments since an important assumption is stationarity of runoff. A detailed review of the different models, applications and assumptions can be found in McGuire and McDonnell (2006).

Other approaches to simulate and analyze TTD include one developed by Kirchner et al. (2001), which combined different transport models (advection-dispersion, exponential and gamma models) and the observed fractal scaling in rainfall and catchment runoff and chemistry in the spectral domain. This approach implies a large number of parameters that are not possible to test in models that are not disaggregated into individually parameterized compartments (Kirchner et al., 2001). Botter et al. (2005) discussed stochastic models that embed spatial variability and uncertainty into a mathematical framework of a reduced number of parameters. They evaluated models including the mass response functions which they suggest as an appropriate generic transport model for catchments. More recently Botter et al. (2010) have explored non-linearities in travel time distributions associated with time-varying rainfall, runoff and evapotranspiration processes, proposing a transport model that considers catchments as nonlinear systems with memory.

Despite the common use of IHS and transit time modeling in hydrology, the combination and integration of the two approaches has not yet been explored. Our approach builds upon the work of McDonnell et al. (1999) and Weiler et al. (1999), whereby the temporal variability in rainfall isotopic composition during an rainfall event is used to model event based transit time distribution (analogous to the annual time series approach of Maloszewski and Zuber, 1982) and to compute event and pre-event water contributions to storm runoff. We thus estimate event water transit time distributions for discrete events (building upon Unnikrishna et al., 1995). In effect, their work was an attempt to combine the process merits of tracer-based hydrograph separation with the hydraulic transfer function approach of the unit hydrograph in an effort to increase the information gained from the storm hydrograph. The new method of hydrograph sepa- ration proposed in this paper embraces the temporal variability of rainfall isotopic composition, but includes a new transfer function for event water and pre-event water determined from the time-variable event water fraction. A transfer function representing the runoff response (i.e. the instantaneous unit hydrograph) is used to constrain the event residence time distribution and the hydrograph components. This transfer function approach overcomes many of the limitations of traditional two-component hydrograph separations (Buttle, 1994) and provides separate representations of runoff and tracer responses to storm events that are used to improve de description of hydrologic processes. We argue in this paper that both responses are essential to understand catchment behavior, since one response (i.e. the transit time) represents actual conservative solute travel time (i.e. along flowpaths) and the other represents hydraulic dynamics (e.g. rainfall-runoff response).

We present a new methodology that combines the isotope hydrograph separation and long term transit time modeling to provide realistic information about the response and transit time of water in catchments over several orders of temporal scales. We use this model to compare the effect of land use on the hydrological response of three small headwater catchments in the mountains of Colombia, that constitute the water source for a municipality of 15000 people.

\section{Methods}

\subsection{Study site and dataset}

Three adjacent small headwater catchments draining to the same river system were selected for a comparative study of land use and stream flow to quantify the impact that different land use types have on stream flow. These catchments are located in the coffee growing region of Colombia (Fig. 1), on the western side of the central branch of the Andes and drain to the Cauca River, which flows north to the Atlantic Ocean. Their elevation ranges from 2000 to $2200 \mathrm{~m}$; the average annual precipitation in the region recorded since 1972 has been approximately $2990 \mathrm{~mm}$ and has a bimodal distribution. Most of the land in the three micro-catchments is dedicated to extensive cattle rearing but differences in land use can be seen among the three catchments. The parent materials of the soil are fluvio-volcanic sediments (mostly clays of uniform size and arranged with pockets of crystalline coarse fragments). The soil has a volcanic ash layer which can reach up to tens of meters in thickness at some locations, is characterized by very low hydraulic conductivity, which contributes to the formation of wetlands, limits water percolation and contributes to maintaining a high water table. Soils formed on these sediments are classified as Andisols (Acrudoxic Hapludans) (IGAC, 1996) characterized by high organic matter content and high content of allophanes 


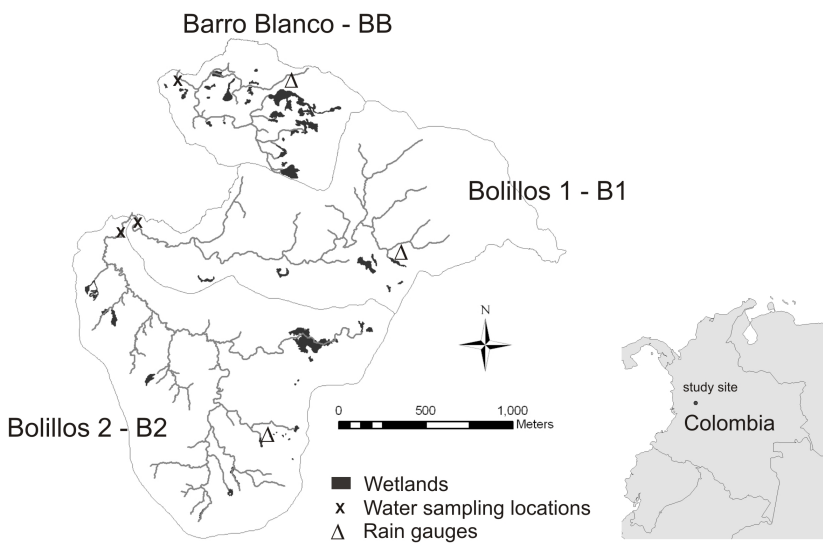

Fig. 1. Location of study site and the three small headwater catchments compared. The detailed map shows he wetlands found in each of the three catchments.

and imogolite, which combined produce soils of high water holding capacity.

The catchments (B1, B2 and BB) differ in size and land use (Table 1). BB is the smallest catchment, but has the largest proportion of wetlands. B2 is the largest catchment with the highest proportion of grasslands. And B1 is smaller than B2 but has a larger proportion of natural and riparian forest.

Streamflow was monitored at the outlet of the three catchments. Water level was recorded every $15 \mathrm{~min}$ from June 2005 until May 2007 with three AquiStar PT2X Smart Sensors@ at the catchment outlet. The water level data series were converted into discharge measurements with stagedischarge relations using 62,44 and 50 discharge measurements for catchments $\mathrm{B} 1, \mathrm{~B} 2$ and $\mathrm{BB}$, respectively. A natural cross-section was used in each of the streams to do the flow measurements with an OTT flow meter. Stage $/ Q$ discharge relationships were obtained as equations of the form $Q=k\left(h-h_{o}\right)^{a}$ using solver in excel (details of these equations can be found in Roa-García, 2009). Average annual discharge during the period of monitoring was $2400 \mathrm{~mm}$ for B1, $2490 \mathrm{~mm}$ for B2 and $2047 \mathrm{~mm}$ for BB. Precipitation was measured using three Hobo Pro data logging rain gauges located in each catchment and precipitation for the thee catchments was $3264 \mathrm{~mm}$ for B1, $3020 \mathrm{~mm}$ for B2 and $3141 \mathrm{~mm}$ for BB. All rain gauges were located on grassland sites at between 2100 and $2135 \mathrm{~m}$ of elevation.

Rain samples were taken every two weeks from November 2005 until May 2007 (n=39). Rain was collected according to guidelines from the isotope hydrology laboratory of the International Atomic Energy Agency - IAEA (IAEA, 2002), to prevent fractionation through temperature variations or direct exchange of rain water with the atmosphere. The water accumulated every two weeks was mixed in the container and a sample was taken at the end of the sampling period. At all stream gauging stations, stream water samples were manually taken every two weeks, from May 2006 to May 2007 $(n=74)$.

An event is defined as precipitation equal or larger than $2 \mathrm{~mm}$ that ends when there has been no precipitation for the following $2 \mathrm{~h}$. Seven storm events were sampled during two rainy seasons in 2006 and 2007, of which five events were selected for modeling due to their completeness: 14 November of 2006 (event 2), 21 November 2006 (event 3), 7 April 2007 (event 5), 18 April 2007 (event 6) and 25 April 2007 (event 7). The rain samples were taken manually and a group of six people participated in the collection of samples for each event. The sequence of rain samples was determined by the speed at which vials could be filled with rain. From the three streams an initial sample was taken before the rain started. Once the water level started rising, samples were taken every 20 min until the peak was reached when another sample was taken. After the peak, four samples were taken every $30 \mathrm{~min}$ and then every two hours until the water level returned to the same water level in the stream previous to the beginning of the storm event. The number of samples was 104 for event 2, 83 for event 3, 71 for event 5, 95 for event 6 , and 86 for event 7 . Precipitation and discharge samples were taken in high density polyethylene scintillation vials with cone caps. The oxygen isotopic composition of samples was determined with a Finnigan Delta XP IRMS and the GasBench II using the classical headspace-equilibration technique. The $\delta^{18} \mathrm{O}$ values are reported in per mil (\%o) relative to the standard (VSMOW) with an analytical error of $\pm 0.08 \%$. Figure 2 shows the isotope signal for each of the three streams for event 2 , showing similarities of isotope signal response for the three streams. Figure 3 shows the comparison between precipitation amount and isotopic composition for the present study. For the long term analysis, the isotopic composition data of precipitation was paired with the long term precipitation data of the closest Global Network of Isotopes in Precipitation (GNIP) stations (Pereira and Bogota). The correlations of the monthly average of precipitation for the period 1971-2007 of this climate station with the precipitation of the present study for the years 2005 and 2006 was of 0.9 and 0.8 and the correlation of the overlapping monthly isotope ${ }_{18} \mathrm{O}$ values were $r^{2}=0.77$.

\subsection{Estimating RTD and TTD for events and baseflow conditions}

The integrative models applied at the two time scales (the short-term, event and the long-term, baseflow scales) estimate the response time distribution (RTD) and the transit time distribution (TTD). These responses are typically decoupled with the displacement of stored water during rainfall periods and the slow drainage during dry periods and the rapid response of new water inputs via well-connected pathways (Bonell, 1998). The Mean Transit Time (MTT) is defined as the average time elapsed since water drops entered 

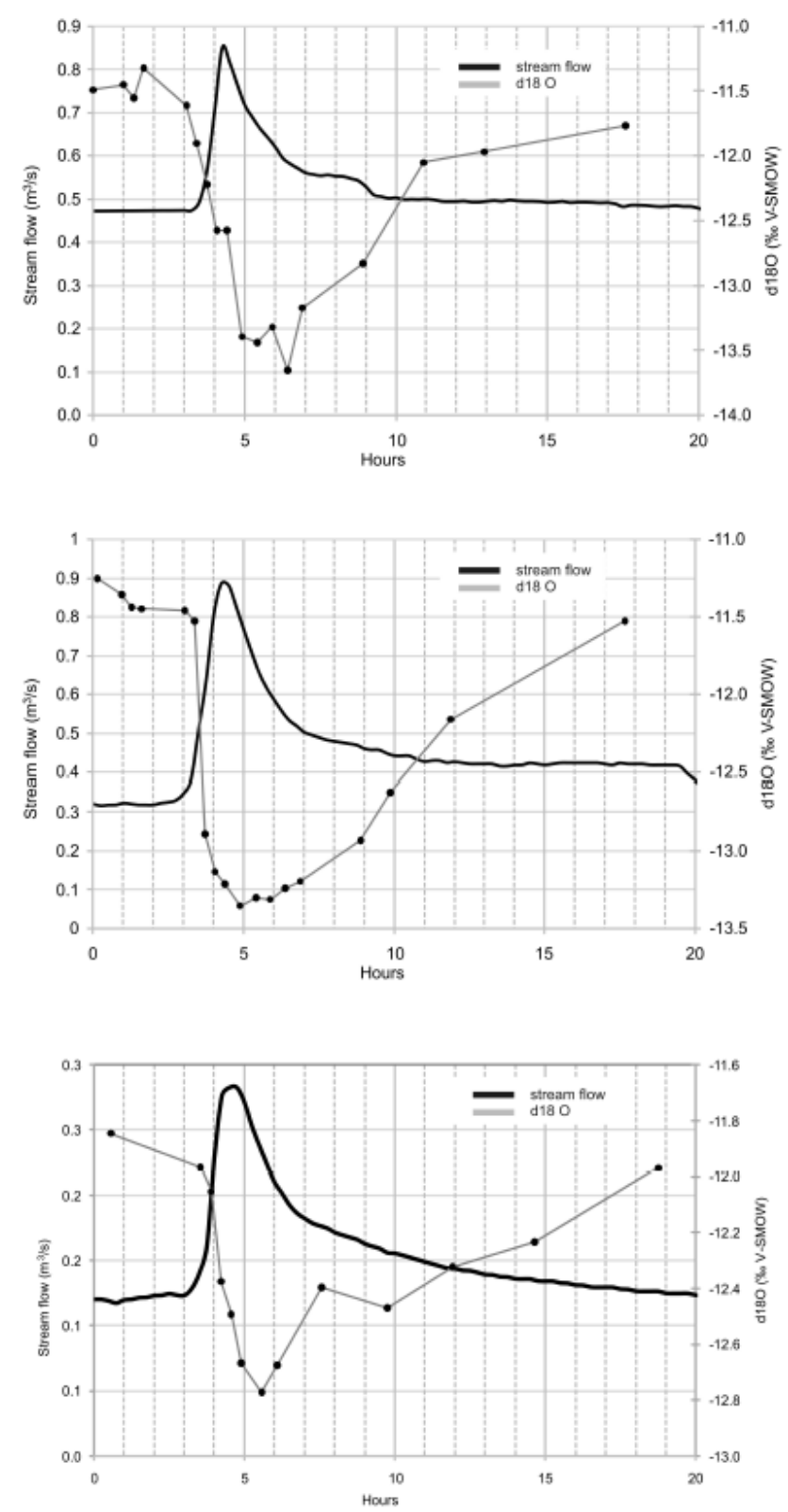

Fig. 2. Stream discharge and stream isotope signal for event 2 for B1 (top), B2 (center) and BB (bottom).

the catchment and the time they are observed in the catchment outlet (Vitvar et al., 2005). Mean Response Time (MRT) on the other hand, is an indicator of the rainfall-runoff response as it represents the speed and volume of outflow with which a catchment responds to water input (precipitation). Since the fluctuations in hydraulic head (the driving force in water flux) can propagate much faster than individual water molecules, the MRT is expected to be shorter than the MTT. The TTD describes the distribution of times that each molecule of water takes to arrive at the catchment outlet from all locations in the catchment (McGuire and Mc-
Table 1. Proportion of land use for each catchment.

\begin{tabular}{lrrrrrr}
\hline & \multicolumn{2}{c}{ B1 } & \multicolumn{2}{c}{ B2 } & \multicolumn{2}{c}{ BB } \\
Areas & ha & $\%$ & ha & $\%$ & ha & $\%$ \\
\hline Riparian and natural forest & 81 & 51 & 49 & 27 & 15 & 25 \\
Plantation forest & 28 & 17 & 2 & 1 & 3 & 5 \\
Grasslands & 48 & 30 & 124 & 69 & 39 & 62 \\
Wetlands & 1 & 1 & 3 & 1 & 4 & 6 \\
Roads and buildings & 1 & 1 & 2 & 1 & 1 & 1 \\
Total area & 159 & 100 & 180 & 100 & 62 & 100 \\
\hline
\end{tabular}

Donnell, 2006). The response time distribution or RTD is the integrated response time of a catchment to a unit rainfall input and is similar to the unit hydrograph concept.

The models to estimate RTD and TTD for individual events and under baseflow condition were further developed from the TRANSEP model, which is a quantitative approach to describe the transit time and transmittance of hydraulic behavior to help understand the relationship between pre-event and event water delivery to streams (Weiler et al., 2003). It uses water flux and isotopic data from precipitation and streamflow to derive transfer functions of runoff, event and pre-event water by capitalizing on the temporal variation of rainfall tracer composition. The transfer function can be chosen from transfer functions previously defined including the exponential distribution, the exponential piston-flow distribution and the advection-dispersion model (Maloszewski and Zuber, 1982), the gamma distribution (Kirchner et al., 2001 ), or the two parallel linear reservoirs model (Weiler et al., 2003). Weiler et al. (2003) tested these models and obtained best results from the two parallel linear reservoirs (TPLR). Other studies (Hrachowitz et al., 2009; McGuire et al., 2005) also showed that the TPLR model produces good results. The TPLR was the transfer distribution used for the present study.

The input data for event analysis with this model corresponds to precipitation intensity and streamflow and the corresponding isotope composition for precipitation and stream flow. Rain for each event was sampled every $15 \mathrm{~min}$ during its duration; and the streams were sampled at irregular intervals for approximately $24 \mathrm{~h}$. The input data for the baseflow analysis with the model corresponds to precipitation and streamflow in daily intervals and using isotope composition records collected every two weeks for 12 months in the streams (May 2006 to May 2007), precipitation isotope composition records collected every two weeks for 19 months (November 2005 to May 2007), and precipitation records of 29 months (January 2005 to May 2007). When the MTT in a catchment is sufficiently longer than the input record, parameters such as MTT will be poorly estimated. With a MTT of around one year, only a record of five years or longer would allow most of the inputs to pass through the catchment and produce a good estimate of these parameters (McGuire 


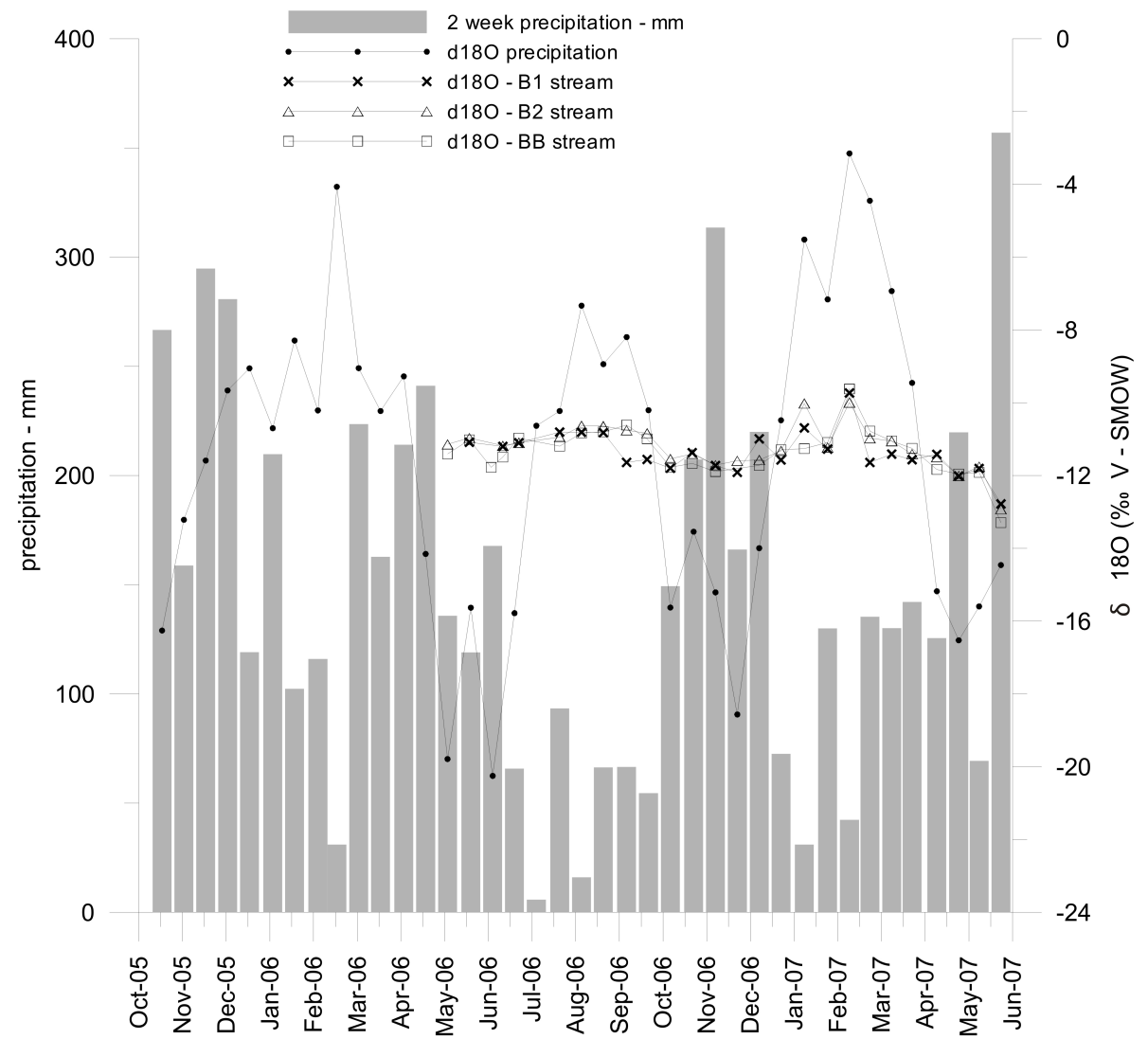

Fig. 3. Isotopic signal in precipitation and streams compared with the amount of precipitation for 2-week periods.

and McDonnell, 2006). Therefore, the input data was extended by correlating the observed isotopic data to the nearest long-term climate station (Bremen, CRQ) and extending the input time series to five years.

The models to estimate RTD for the short and long time scale are both simple runoff models that simulate streamflow by a non-linear and a linear module, similar to a variety of instantaneous unit hydrograph (IUH) based models (Bras, 1990). The non-linear module is the loss function generating an effective precipitation time series (Jakeman and Hornberger, 1993):

$s(t)=b_{1} p(t)+\left(1-b_{2}^{-1}\right) s(t-\Delta t)$

$p_{\text {eff }}(t)=p(t) s(t)$

where $p_{\text {eff }}(t)$ is the effective precipitation, $s(t)$ is the antecedent precipitation index that is calculated by exponentially weighting the precipitation backward in time according to the parameter $b_{2}$. The parameter $b_{1}$ scales the total simulated runoff over the simulation period (similar to a runoff coefficient) and thus can be determined directly from the rainfall- runoff data. The runoff coefficient rc for each temporal scale can be defined as the total effective precipitation divided by the total precipitation. The runoff coefficients for the events are a reflection of runoff generation processes and storage; for the longer time scale, the difference between precipitation and effective precipitation is due to evapotranspiration. The linear module describes a convolution of the effective precipitation and runoff transfer function:

$Q(t)=\int_{0}^{t} g(\tau) p_{\mathrm{eff}}(t-\tau) d \tau$

where $g(\tau)$ is the response time distribution (RTD), defined for the long term $(b)$ and event $(e)$ scale, and thus the rainfallinduced response of catchment runoff.

To estimate the streamflow concentration $C(t)$ for the baseflow model we use the tracer mass flux instead of the tracer concentration since the tracer signal depends on the actual tracer mass flux, which depends on the effective precipitation (Stewart and McDonnell, 1991; Weiler et al., 1999):

$C(t)=\frac{\int_{0}^{t} C_{\mathrm{in}}(t-\tau) p_{\mathrm{eff}}(t-\tau) h_{b}(\tau) d \tau}{\int_{0}^{t} p_{\mathrm{eff}}(t-\tau) h_{b}(\tau) d \tau}$

where $h_{b}(\tau)$ is the long-term transit time distribution and $C_{\mathrm{in}}$ is the observed input concentration in the precipitation. As introduced into the TRANSEP model, the event water transit time distribution $h_{e}(\tau)$ can be calculated in a similar way by focusing on individual events and including the effect of 
event and pre-event water runoff during the events. The concentration $C(t)$ in the stream is then given by (Weiler et al., 2003):

$C(t)=\frac{\int_{0}^{t} C_{\text {in }}(t-\tau) p_{\text {eff }}(t-\tau) f(t-\tau) h_{e}(\tau) d \tau}{\int_{0}^{t} p_{\text {eff }}(t-\tau) f(t-\tau) h_{e}(\tau) d \tau}$

The main difference to Eq. (4) is $f$, the fraction of effective precipitation that becomes event water (i.e. "new" water), and $h_{e}(\tau)$ is the transfer function of the event water (i.e. the transit time distribution). The denominator of Eq. (5) is equal to the event water runoff (Weiler et al., 2003) and the total event water fraction $F$ can then be derived. The units of nominator and denominator of Eq. (5) are (Volume/Time) to calculate the event water fraction.

As already discussed we use the two parallel linear reservoirs as our transfer function for the RTD and TTD and for both time scales:

$g(\tau)=h_{b}(\tau)=h_{e}(\tau)=\frac{\phi}{\tau_{f}} \exp \left(-\frac{\tau}{\tau_{f}}\right)+\frac{1-\phi}{\tau_{s}} \exp \left(-\frac{\tau}{\tau_{s}}\right)$

Where $\tau_{f}$ and $\tau_{s}$ are the mean response or transit times of the fast and slow responding reservoirs, respectively. The parameter $\phi$ defines the partition of the input into the fast responding reservoir.

We used ant colony optimization to the inverse estimation problem of the unknown parameters (Abbaspour et al., 2001) for both time scales. It has been shown that this technique efficiently finds the optimum solution for a wide range of applications. First, the parameter of the response time model was optimized using precipitation as input and streamflow as output. Second, the parameters of the transfer time model were optimized adding the observed isotope concentration for precipitation and streamflow. This stepwise optimization technique ensures that the inverse problem is not ill posed and that the parameters are identifiable (Weiler et al., 2003).

\subsection{Combining RTD and TTD from events and baseflow modeling}

The estimated RTD and TTD for the two time scales (minutes for the events and days for the baseflow) are describing a hydrological system (i.e. watershed) with different temporal resolution. In order to derive a RTD or TTD distribution that describes a catchment from minutes to years, we can combine the two distributions for the events and the baseflow. To do this, we select the distribution from an individual event and combine it with the overall distribution from the baseflow analysis. This can be done for different events and the RTD or TTD will show the time variant behavior of the catchment according to the event characteristics. This is similar to the observations made by McGuire et al. (2007). The combined RTD $(g \tau)$ and TTD $h(\tau)$ is then given by:

$g(\tau)=r c_{e} g_{e}(\tau)+\left(1-r c_{e}\right) g_{b}(\tau)$

$h(\tau)=\left[r c_{e} F h_{e}(\tau)+\left(1-r c_{e} F\right) h_{b}(\tau)\right] r c_{b}$
The integral of the RTD will be unity, but as can be seen in Eq. (8), the integral of the TTD can be less than unity. The idea behind this new concept is that for an open system like a catchment, part of the water molecules entering the system as precipitation will leave the catchment not through the stream but by evapotranspiration. Hence, a TTD can in a strict way not approach unity for most catchments as part of the water molecules that entered the system during a precipitation event never reach the stream. This idea is similar to the stochastic concept of an evapotranspiration time probability distribution function pdf proposed by Botter et al. (2010).

\section{Results}

\subsection{RTD and TTD of rainfall-runoff events}

Five sampled storms were analyzed using TRANSEP for the three catchments. The results are shown in Table 2. Results include event water, defined as the proportion of stream discharge during an event that originates from precipitation (Buttle, 1994) and runoff coefficient which corresponds to the proportion of rainfall that becomes stream discharge during an event. For each of the two processes (transit of individual water molecules and the response of catchments) three parameters are optimized: the transit/response time of the fast reservoir $\left(\tau_{\mathrm{f}}\right)$, the transit/response time of the slow reser$\operatorname{voir}\left(\tau_{\mathrm{s}}\right)$ and the portion of the total discharge corresponding to the fast reservoir $(\Phi)$ for individual events.

The model was generally able to predict the observed runoff response as the Nash-Suttcliff Efficiency is larger than 0.8 for almost all events. As shown in Table 2, efficiency values of the simulation indicate that the prediction of the isotopes variation in the streamflow with TRANSEP was also acceptable. Generally, the RTD is dominated by the fast reservoir with a very rapid response time below $1 \mathrm{~h}$. The TTD is prolonged over a longer period, but dominated by the fast reservoir. For a couple of events, the two linear reservoirs are simplified to an exponential model since the portion of the total discharge corresponding to the fast reservoir is equal to unity.

There is not a large difference in pre-event water between B1 (forest dominated catchment) and B2 (grassland dominated catchment). Catchment BB however, seems to produce larger pre-event water, which could be linked to the presence of wetlands in the catchment area. Catchments B2 and $\mathrm{BB}$ are relatively similar in their runoff coefficients while B1's seem significantly lower. Catchments B2 and BB have similar distribution of land coverage, with grasslands as the dominant land use (69\% and $62 \%$, respectively) the difference being the percentage of wetland area $(6 \%)$. The lower $\mathrm{RC}$ of B1 suggests the significant effect of forests in the retention of rain events. 
Table 2. Parameters of response and transit time model applied to individual events.

\begin{tabular}{|c|c|c|c|c|c|c|c|c|c|c|c|c|c|c|c|c|c|}
\hline \multirow[b]{2}{*}{ Event } & \multirow[b]{2}{*}{ Catchment } & \multirow{2}{*}{$\begin{array}{l}\text { total } \\
\text { rain in } \\
\text { event } \\
(\mathrm{mm})\end{array}$} & \multicolumn{2}{|c|}{$\begin{array}{l}\text { Antecedent } \\
\text { precipitation } \\
(\mathrm{mm})\end{array}$} & \multirow{2}{*}{$\begin{array}{c}\text { Max } \\
\text { I15 } \\
(\mathrm{mm})\end{array}$} & \multirow{2}{*}{$\begin{array}{l}\text { Event } \\
\text { water }\end{array}$} & \multirow{2}{*}{$\begin{array}{l}\text { Measured } \\
\text { RC }\end{array}$} & \multirow{2}{*}{$\begin{array}{l}\text { Simulated } \\
\text { RC }\end{array}$} & \multirow{2}{*}{$\begin{array}{c}\mathrm{Q} \\
\text { Efficiency }\end{array}$} & \multirow{2}{*}{$\begin{array}{c}C \\
\text { Efficiency }\end{array}$} & \multirow[b]{2}{*}{$\tau_{\mathrm{f}}(\mathrm{h})$} & \multirow{2}{*}{$\begin{array}{l}\text { TTD } \\
\tau_{\mathrm{S}}(\mathrm{h})\end{array}$} & \multirow[b]{2}{*}{$\Phi(-)$} & \multirow[b]{2}{*}{$\tau_{\mathrm{f}}(\mathrm{h})$} & \multirow{2}{*}{$\begin{array}{l}\text { RTD } \\
\tau_{\mathrm{s}}(\mathrm{h})\end{array}$} & \multirow[b]{2}{*}{$\Phi(-)$} & \multirow{2}{*}{$\begin{array}{c}\mathrm{N}- \\
\text { isotope } \\
\text { Samples }\end{array}$} \\
\hline & & & 1 day & 3 days & & & & & & & & & & & & & \\
\hline 2 & B1 & 24 & 18 & 88 & 5 & $23 \%$ & $10 \%$ & $10 \%$ & 0.95 & 0.68 & 2.2 & 82 & 0.70 & 0.1 & 1.6 & 0.65 & 18 \\
\hline 6 & B1 & 38 & 2 & 5 & 10 & $24 \%$ & $11 \%$ & $10 \%$ & 0.85 & 0.63 & 1.5 & 120 & 1.00 & 0.1 & 2.2 & 0.73 & 19 \\
\hline 7 & B1 & 30 & 14 & 30 & 14 & $32 \%$ & $5 \%$ & $5 \%$ & 0.54 & 0.86 & 1.5 & 82 & 0.70 & 0.1 & 2.1 & 0.40 & 11 \\
\hline 2 & B2 & 24 & 16 & 66 & 3 & $25 \%$ & $21 \%$ & $20 \%$ & 0.90 & 0.78 & 4.7 & 120 & 0.60 & 0.1 & 1.1 & 0.47 & 18 \\
\hline 5 & B2 & 24 & 1 & 3 & 6 & $40 \%$ & $14 \%$ & $13 \%$ & 0.80 & 0.86 & 2.3 & 40 & 0.88 & 0.1 & 2.1 & 0.62 & 19 \\
\hline 6 & B2 & 31 & 2 & 5 & 11 & $21 \%$ & $28 \%$ & $27 \%$ & 0.98 & 0.48 & 0.6 & 95 & 0.30 & 0.1 & 0.6 & 0.47 & 16 \\
\hline 2 & $\mathrm{BB}$ & 16 & 35 & 95 & 4 & $12 \%$ & $25 \%$ & $25 \%$ & 0.96 & 0.48 & 3.3 & 120 & 1.00 & 0.1 & 2.4 & 0.78 & 13 \\
\hline 3 & BB & 21 & 7 & 29 & 9 & $27 \%$ & $36 \%$ & $36 \%$ & 0.95 & 0.88 & 1.8 & 120 & 0.97 & 0.1 & 2.3 & 0.80 & 15 \\
\hline 5 & BB & 16 & 1 & 6 & 7 & $14 \%$ & $19 \%$ & $19 \%$ & 0.76 & 0.59 & 2.7 & 120 & 0.90 & 0.1 & 1.8 & 0.69 & 15 \\
\hline
\end{tabular}

$\mathrm{RC}=$ runoff coefficient

Efficiency = Nash-Sutcliffe Efficiency (unitless with a maximum of (1) providing a goodness-of-fit measure between observed and simulated discharge (Q)

and isotope concentrations $(C)$

$\tau_{\mathrm{f}}(\mathrm{h})=$ Transit or response time of fast reservoir

$\tau_{\mathrm{S}}(\mathrm{h})=$ Transit or response time of slow reservoir

$\Phi(-)=$ Portion of fast reservoir

Table 3. Parameters of response and transit time model applied to baseflow.

\begin{tabular}{llllllllllll}
\hline & & \multicolumn{3}{c}{ TTD } & \multicolumn{3}{c}{ RTD } \\
& $\begin{array}{l}\text { Measured } \\
\text { RC }(\%)\end{array}$ & $\begin{array}{l}\text { Simulated } \\
\text { RC }(\%)\end{array}$ & $\begin{array}{l}\mathrm{Q} \\
\text { efficiency }\end{array}$ & $\begin{array}{l}C \\
\text { efficiency }\end{array}$ & $\begin{array}{l}\tau_{\mathrm{f}} \\
(\text { days })\end{array}$ & $\begin{array}{l}\tau_{\mathrm{s}} \\
(\text { days })\end{array}$ & $\Phi(-)$ & $\begin{array}{l}\tau_{\mathrm{f}} \\
(\text { days })\end{array}$ & $\begin{array}{l}\tau_{\mathrm{s}} \\
(\text { days })\end{array}$ & $\begin{array}{l}\text { N-isotope } \\
\text { samples }\end{array}$ \\
\hline B1 & $68 \%$ & $72 \%$ & 0.62 & 0.82 & 15 & 639 & 0.01 & 5.0 & 500 & 0.64 & 25 \\
B2 & $76 \%$ & $76 \%$ & 0.57 & 0.89 & 10 & 639 & 0.01 & 1.6 & 50 & 0.37 & 26 \\
BB & $62 \%$ & $63 \%$ & 0.59 & 0.79 & 10 & 639 & 0.04 & 1.6 & 500 & 0.34 & 25 \\
\hline
\end{tabular}

$\mathrm{RC}=$ runoff coefficient

Efficiency = Nash-Sutcliffe Efficiency (unitless with a maximum of 1) providing a goodness-of-fit measure between observed andsimulated discharge (Q)

and isotope concentrations $(C)$

$\tau_{\mathrm{f}}(\mathrm{h})=$ Transit or response time of fast reservoir

$\tau_{\mathrm{S}}(\mathrm{h})=$ Transit or response time of slow reservoir

$\Phi(-)=$ Portion of fast reservoir

Antecedent precipitation combined with the size of the event, are major factors in determining the percentage of event water in the total discharge. Event 2 happened during relative wet antecedent conditions $(66-95 \mathrm{~mm}$ within 3 days) producing relatively small event water contributions in all catchments, particularly in BB with the wettest antecedent conditions. All other events are characterized by drier antecedent conditions and generate, in general, more event water combined with a smaller runoff coefficient. Analysis of more events would have been necessary to provide a more consistent picture among the factors influencing runoff generation and event water contribution.

\subsection{RTD and TTD of baseflow}

Results of the Transit Time model for the baseflow samples taken every two weeks are shown in Table 3. The three catchments have relatively high yields. Runoff coefficient - RC is defined as the proportion of rainfall that becomes stream discharge on an annual basis. B2, with a $\mathrm{RC}$ of $76 \%$ is the catchment with the smallest infiltration and storage capac- ity when it rains, and thus a larger proportion of rainfall becomes runoff. $\mathrm{BB}$, despite having a similar percentage of forest cover than B2, has the lowest RC, pointing to the higher proportion of wetland area that would contribute to store water and preventing a higher proportion of runoff.

The mean response times of baseflow correspond to the result of the model using a 1-day step to obtain the slower response of the streamflow to precipitation. They indicate that the water that enters B2 catchment takes 28 days to reach the catchment outflow, being the catchment with the shortest mean response time; the water that enters B1 takes 97 days to leave the catchment and for BB catchment, the water takes 172 days to leave. The wetlands in BB could be the main explanation for the longer mean response time of water in $\mathrm{BB}$; and the forests in B1 could explain the intermediate response time of water for this catchment. The separation of the input water into the slow and the fast compartments shows that it is the mean response time of the slow reservoir that is significantly shorter for B2 than for the other two catchments (50 days versus 500 days), which draws down the total mean 

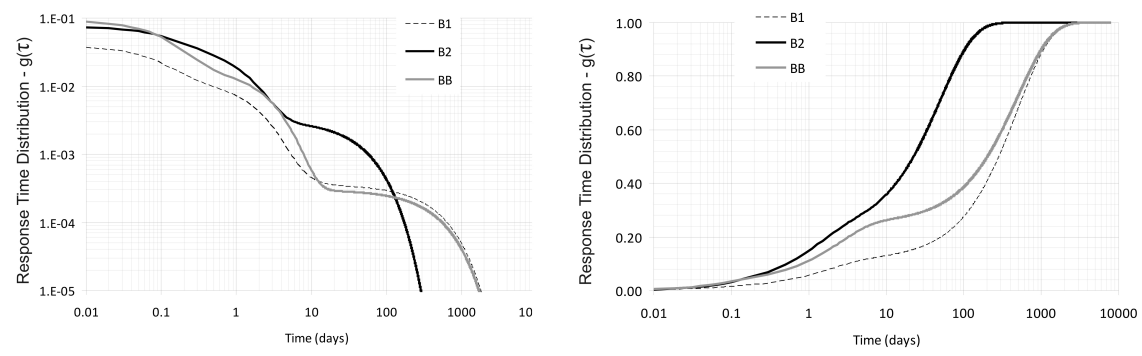

Fig. 4. Response Time Distribution - RTD for the three catchments for event 2: probability density function - pdf (left), cumulative density function - cdf (right).
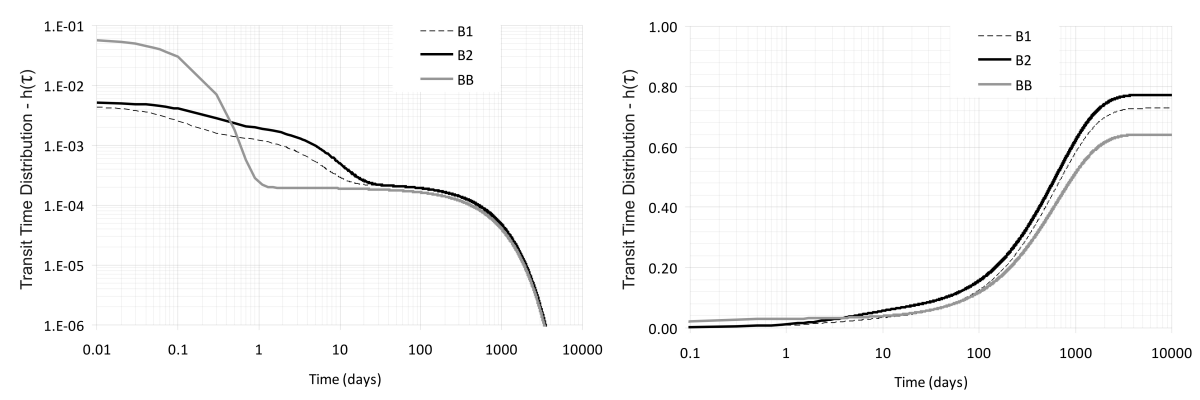

Fig. 5. Transit Time Distribution - TTD for the three catchments for event 2: probability density function - pdf (left), cumulative density function - cdf (right).

response time for B2. Catchment B2, despite a relatively large slow reservoir portion, has a short MRT due to its short MRT for the slow reservoir.

\subsection{Comparing integrated RTD and TTD}

The integration of event and baseflow data to generate RTD and TTD allows a comparison of catchments on a long time scale by incorporating the influence of individual events. Figure 4 compares the response of the three studied catchments for event 2 , which was a relatively large event in catchments B1 and B2 where 1-day antecedent precipitation was low and a medium size event for catchment BB (Table 2) where 1-day antecedent precipitation was higher. The resulting RTD curves which illustrate the hydrological response of the catchments show a significantly shorter RTD for catchment B2. This is influenced by the land use differences between the three catchments, since B2 is the catchment dominated by grasslands with a more limited water storage capacity than the catchments dominated by forest or with a significant portion of wetlands. Additionally the curves show the effect that antecedent precipitation conditions have on RTD at the short time scale. These curves also show that B1, the forest dominated catchment, had the slowest response and hence the largest overall storage.
Differences between the TTD of the three catchments can be seen in the probability and cumulative distribution function of the TTD as shown in Fig. 5. The large differences observed between the three catchments for the short times are determined by the runoff coefficients of the different events, which in turn respond to the influence of the size and intensity of the event and the antecedent precipitation conditions in each of the catchments. The cumulative TTD in the longer time scale show the influence of vegetation on the total evapotranspiration flux which in turn influences the total amount of water that leaves the catchment by streamflow. The three curves show that the catchment with the highest percentage of wetlands (BB) is the catchment that looses more water in the longer time range through evapotranspiration, followed by the catchment dominated by forests (B1). Also the catchment with the highest proportion of wetlands (BB) has the highest proportion of water leaving the watershed within the first day.

The comparison of RTD for the three catchments for different events, shown in the left column of Fig. 6, illustrates similarities between catchments B2 and BB in terms of the pdf at short times (revolving around 0.1 ) in contrast to the pdf of B1 with values below around 0.01 . These pdfs highlight the impact of forests (B1) on water holding capacity and the dampening of storm flows. For the larger times, a difference can be seen between B2 (the grass land catchment) and the 

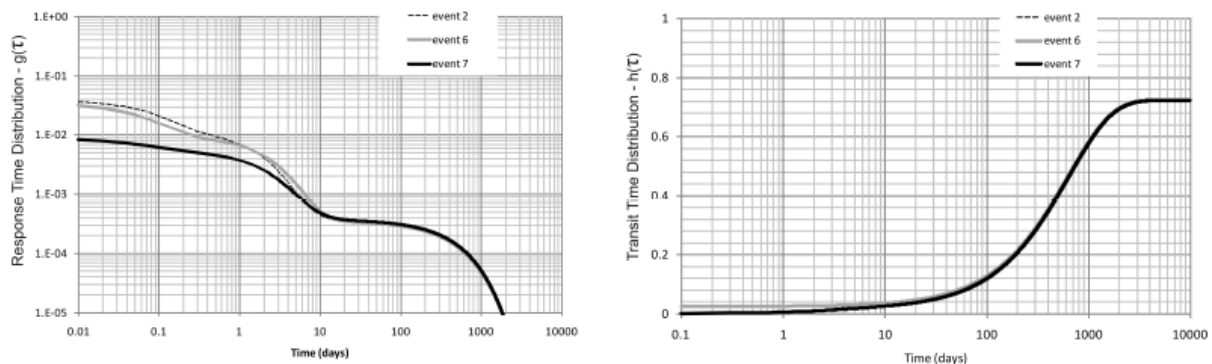

B) B2
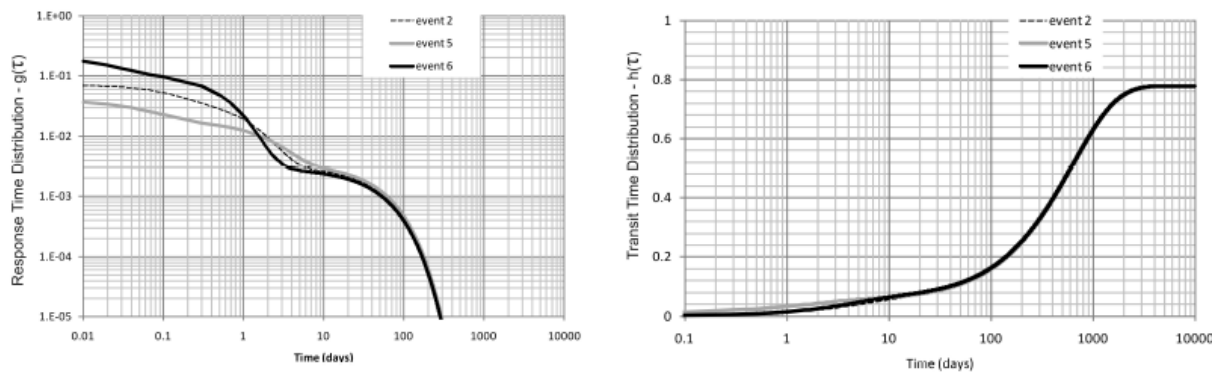

C) $\mathrm{BB}$
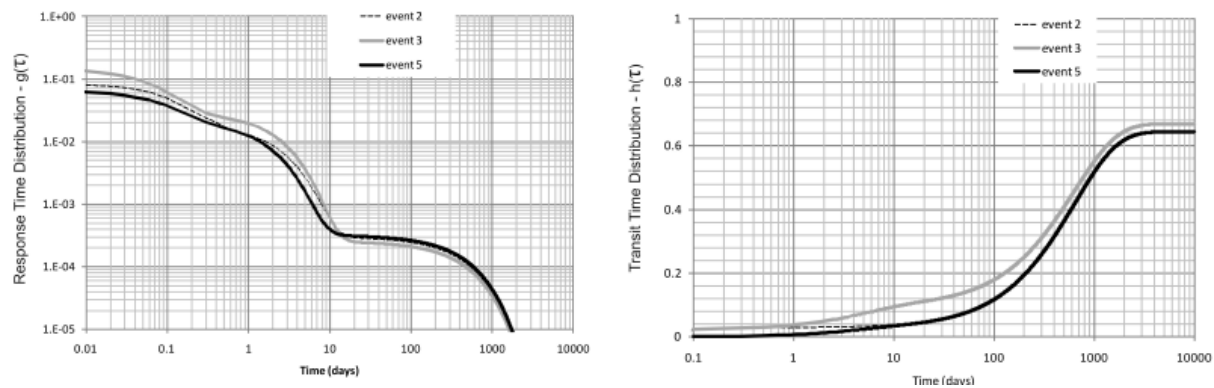

Fig. 6. Probability density function - pdf of Response Time Distribution (RTD $-g(T)$ ) and cumulative probability density function - pdf of Transit Time Distribution (TTD $-h(T)$ ) in the left and right columns, respectively.

other two catchments that show a higher frequency of longer response suggesting the influence of forests and wetlands as a long term water storage.

The comparison of the cumulative TTD for the individual catchments in the right column of Fig. 6 shows a similar picture as for the RTD, but the variability of cumulative event water contribution among rainfall events is much smaller than the variability of runoff response and runoff coefficients among events. In the right column of Fig. 6 it is shown that the proportion of water leaving the watershed within the first 10 days is very similar for most events and below $10 \%$ for all watersheds, but smaller for B1. It is also apparent that BB looses more water to evapotranspiration, as the cumulative TTD in the longer time scale is smaller than for the other two catchments.

\section{Discussion}

\subsection{A new response time and transit time distribution}

According to a transit time study conducted with the use of chloride as a tracer for the Plynlimon catchments near the coast of Wales (Kirchner et al., 2001), the gamma distribution is an empirically adequate description of the attenuation of chloride concentration from the rainfall to the streamflow. This distribution has also proven to be a robust description of the transit time in many other catchments (Kirchner et al., 2001; Hrachowitz et al., 2009; Hrachowitz et al., 2009b). A gamma distribution is fitted to the observed TTD for event 2 of the three watersheds in Fig. 7 using the runoff coefficient to reduce the integral of unity to 0.74 . The two parameters of the gamma distribution, $\alpha$ and $\beta$ were estimated as 0.7 and 800 , resulting in a MTD of 560 days. The range of $\alpha$ between 0.5 and 1.0 is in accordance to the observations made in other watersheds. However, the gamma distribution does not adequately describe the short term behavior 

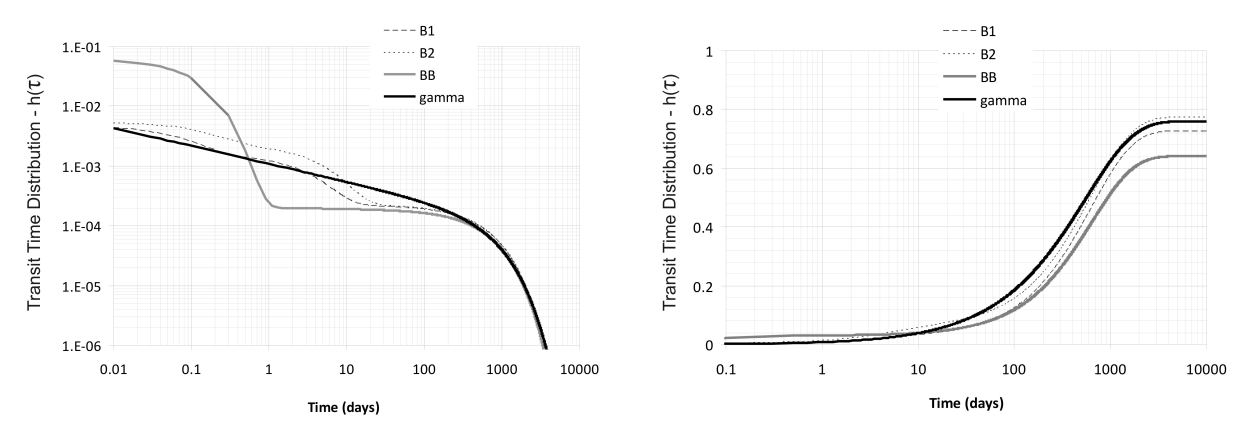

Fig. 7. Transit Time Distribution - TTD for the three catchments for event 2 as shown in Fig. 3 but including a fitted gamma distribution (black line): probability density function - pdf (left) and cumulative density function - cdf (right).

of the TTD in most cases. This implies that the movement of water in short time spans (less than 10 days) is significantly influenced by individual precipitation events and the dynamics of rainfall-runoff response processes as also shown by McGuire et al. (2007). The method implies that TTD of catchments are not necessarily represented through gamma distributions as has been suggested earlier (Kirchner et al., 2001). It also highlights the issue of applying a steady-state model to catchments over different time scales. Applying any time-invariant TTD to a system that is time-variant at a certain time scale will result in a poor description of the system. Depending on the precipitation regime, the boundary conditions of a catchment may change particularly at the event time-scale (i.e. wetness or vegetation-cover) or at longer time-scales in climates with a distinct rainy and dry season. In our approach, we assumed a time-invariant model for the long-term baseflow model, knowing that this is not necessarily the case, and assumed a time variant approach for the short-term, event time scale TTD. We believe that a long-term time-invariant model can only be applied if the isotope time series is many years long (which was not the case in this study). By comparing the introduced approach to the frequently applied time-invariant Gamma model we intended to show that the combined TTD are not necessarily very different from a Gamma distribution, but that the combined TTD can capture the time-invariant situation for individual event and the short time scales. In addition, the resolution of sampling could influence the results in particular for the shorter time scales. The integration of event TTD with a high resolution of sampling of isotope composition for individual events allows seeing differences in catchment responses at both the short and the long time spans. The combination of high frequency sampling (events) with lower frequency sampling (baseflow) is possible with the processbased approach presented here but has to be applied carefully when using spectral analysis (Feng et al., 2004).

\subsection{How to compare catchments}

The integration of the two time scales is proposed here as a new tool to compare catchments. Although only individual events can be incorporated into the approach, the resulting RTD and TTD provide a comprehensive image of the catchment response over a long time range for the hydraulic and isotopic processes. The proposed method allowed a comparison between catchments for several events and showed that incorporating individual events into a longer time frame provides a comprehensive view of water movement in catchments.

Comparisons at different time scales have been done for several years. Hydrograph separation of events using TRANSEP illustrated the differences that land use has on water flow regulation and the source of water during storm events. Two main findings arise from this comparison: (1) the grassland dominated catchment B2 has a higher event response in relation to the forest dominated catchment B1, but both of them show a similar composition of event and preevent water; and (2) even a small percentage of area in wetlands ( $6 \%$ of catchment area for BB) drain a high percentage of old water during storm events related to the higher connectivity of saturated areas to the discharge network. These findings coincide with what has been found in previous studies both in temperate environments (Genereux and Hooper, 1998) and in tropical environments (Goller et al., 2005 and Johnson et al., 2007). Comparative studies conducted to identify the effects of disturbance or land use change on the hydrograph separation have been few (Buttle and McDonnell, 2005) but in general they show the effects of surface compaction in increasing event water discharge (Gremillion et al., 2000). The results of the present study in relation to the role of wetlands in influencing event discharge of the catchments in which they are located is also in line with results found in similar studies where wetlands increase pre-event water as in Zimbabwe (McCartney et al., 1998) and in boreal catchments (Laudon et al., 2007). The effects of deforestation on runoff coefficient (percentage of volume of water flowing to the catchment outflow compared with the event 
precipitation) have been shown in other studies (Bariac et al., 1995) suggesting the effect of interception and the action of vegetation on soil porosity. An alternative to the empirical quantification of land use change could be the application of physical-based models that simulate water movement and hence the TTD spatially explicit (grid-based approach) in different hydrological compartments (soil water, groundwater, lakes and streams). These models have either been focusing on longer-term TTD (Darracq et al. 2010; Destouni et al., 2010) or on shorter-term applications (Vaché and McDonnell, 2005; McGuire et al., 2007). Similar to the applications of simpler models, water isotope composition could be used to test the applicability of these complex models to predict catchment response to precipitation and to study the influence of land use change on the water flow pathways and transit times.

The analysis of baseflow samples through the proposed model allowed establishing differences in terms of the proportions of fast and slow sources of water in baseflow and the time that water spends in each catchment, to compare the three neighboring catchments with similar topography and size. Results indicated that for B1, the catchment with $68 \%$ of area in forest, discharge comes predominantly from the fast reservoir (64\%) with a response time of five days, whereas for the other two catchments, the fast reservoir constitutes between $34 \%$ and $37 \%$ of total baseflow and have a response time of 2 days. The mean response time of water in catchment BB, 172 days compared with 97 days for B1 (the forested catchment) and 28 days for B2 (the catchment with $69 \%$ in grasslands) is influenced by the longer transit time of water in wetlands (Roa-García, 2009). The difference in the resulting yields for each catchment provides an idea of their overall water holding capacity. Catchment B2, with a larger proportion of grasslands, had the highest yield. This may be explained by lower rates of infiltration in compacted soils under grazed grasslands that produce higher rates of stream discharge during rain events. In general, it appears that the area in wetlands makes a contribution to reducing yield in catchment BB. Lower RC for individual events contributes to reducing the overall yield of this catchment. Results suggest that in general the storage capacity of forests and soils under forests is higher, but during an event old water is pushed out of wetlands in a higher proportion than from riparian and natural forests. The comparison of the isotopic analysis for baseflow and for events indicates the differences in hydrological response at different time scales. The baseflow analysis has a longer time scale (1.5 years) and the event analysis takes individual storms. The results for runoff coefficient of the event analysis corresponds to only five events. The comparison showed that $\mathrm{BB}$ is the catchment with the lowest yield at the baseflow scale and B1 is the catchment with the lowest $\mathrm{RC}$ at the event scale.

\section{Conclusions}

The use of isotope signals in precipitation and stream discharge for the simulation of catchment response to water inputs through RTD and TTD provides a tool to compare catchments and the effects of land use on runoff at continuum temporal scales. The use of a method that integrates two temporal scales (events and baseflow) and two distinct catchment processes (hydrological response and transport) provides a valuable description of water movement in catchments. In addition, the combined TTD will not approach unity since in an open system like a catchment, part of the water molecules entering the system as precipitation will leave the catchment not through the stream but by evapotranspiration. The use of this method to compare neighboring catchments has proved useful to isolate the effects of land use change on the response and transit time of water in small catchments. Isotope applications in hydrology have been used to understand hydrological processes with the goal of providing information to modelers about the way water moves in a catchment. This study has used stable isotope data to compare the effects of land use on stream discharge and water composition, in order to provide water purveyors with information that can be used to protect their water source.

Wetlands are catchment components where water is stored for longer periods of time than in other catchment compartments, prolonging the mean response time of water in their catchments and reducing annual yields. Forests soils also appear to increase the response time of water but to a less extent than wetlands. The forested catchment has a more consistent behavior, showing that even for large events it has a capacity to ameliorate storm flows. The distinct response of catchments to rain events was demonstrated through various indicators and the influence of antecedent precipitation conditions and the characteristics of individual events were clearly shown in the RTD and TTD in the short time scale, while the influence of land use differences was appreciated both in the short and long time scales.

Acknowledgements. This study was funded by the International Foundation for Science - IFS, The United States Agency for International Development - USAID, the International Center for Tropical Agriculture - CIAT and the International Development Research Center - IDRC. We thank the Filandia team for sample collection, the Idaho Stable Isotope Laboratory for sample analysis, and S. Brown, L. Lavkulich and H. Schreier for reviewing the work at various stages.

Edited by: E. Zehe 


\section{References}

Abbaspour, K. C., Schulin, R., and van Genuchten, M. T.: Estimating unsaturated soil hydraulic parameters using ant colony optimization, Ad. Water Resour., 24, 827-841, 2001.

Bariac, T., Millet, A., Ladouche, B., Mathieu, R., Grimaldi, C., Grimaldi, M., Hubert, P., Molicova, H., Bruckler, L., Bertuzzi, P., Boulegue, J., Brunet, Y., Tournebize, R., and Granier, A.: Stream hydrograph separation on two Guianese catchments, Tracer Technologies for Hydrological Systems (Proceedings of a Boulder Symposium), International Association of Hydrological Sciences - IAHS Publ., No. 229, 193-209, July 1995.

Barnes, B. S.: Discussion of analysis of run-off characteristics by O. M. Meyer, Trans. Am. Soc. Civ. Eng., 105, 104-106, 1940.

Bonell, M.: Selected challenges in runoff generation research in forests from the hillslope to headwater drainage basin scale, J. Am. Water Resour. Assoc., 34, 765-786, 1998.

Botter, G., Bertuzzo, E., Bellin, A., and Rinaldo, A.: On the Lagrangian formulations of reactive solute transport in the hydrologic response, Water Resour. Res., 41, W04008, doi:10.1029/2004WR003544, 2005.

Botter, G., Bertuzzo, E., and Rinaldo, A.: Transport in the hydrologic response: travel time distributions, soil moisture dynamics and the old water paradox, Water Resour. Res., 46, W03514, doi:10.1029/2009WR008371, 2010.

Bras, R.: Hydrology, An introduction to hydrologic science, Addison Wesley, Reading, Mass., 643 pp., 1990.

Buttle, J. M.: Isotope hydrograph separations and rapid delivery of pre-event water from drainage basins, Prog. Phys. Geog., 18, 16-41, 1994.

Buttle, J. M. and McDonnell, J. J.: Isotope tracer in catchment hydrology in the humid tropics, in Forest, water and people in the humid tropics, edited by: Bonel, M., and Bruijnzeel, L. A., UNESCO, Cambridge, 2005.

Clark, C.O.: Storage and the unit hydrograph, Trans. Am. Soc. Civ. Eng., 110, 1419-1446, 1945.

Darracq, A., Destouni, G., Persson, K., Prieto, C., and Jarsjö, J.: Quantification of advective solute travel times and mass transport through hydrological catchments, Environ. Fluid Mech., 10(1), 103-120, 2010.

Destouni, G., Persson, K., Prieto, C., and Jarsj, J.: General Quantification of Catchment-Scale Nutrient and Pollutant Transport through the Subsurface to Surface and Coastal Waters, Environ. Sci. Technol., 44 (6), 2048-2055, 2010

Feng, X., Kirchner, J. W. and Neal, C.: Spectral analysis of chemical time series from long-term catchment monitoring studies: hydrochemical insights and data requirements, Water Air Soil Poll.: Focus, 4, 221-235, 2004.

Genereux, D. P. and Hooper, R. P.: Oxygen and hydrogen isotopes in rainfall-runoff studies, in Isotope Tracers in Catchment Hydrology, edited by: Kendall, C. and McDonnell, J. J., Elsevier, Amsterdam, 840 pp., 1998.

Gremillion, P., Gonyeau, A. and Wanielista, M.: Application of alternative hydrograph separation models to detect changes in flow paths in a watershed undergoing urban development, Hydrol. Process., 14, 1485-1501, 2000.

Goller, R., Wilcke, W., Leng, M. J., Tobschall, H. J., Wagner, K., Valarezo, C., and Zech, W.: Tracing water paths through small catchments under a tropical montane rain forest in south Ecuador by an oxygen isotope approach, J. Hydrol., 308(1-4), 67-80,
2005.

Hewlett, J. D. and Hibbert, A. R.: Factors affecting the response of small watersheds to precipitation in humid areas, in Forest Hydrology, edited by Sopper, W. E. and Lull, H. W., Pergamon, New York, USA, 275-291, 1967.

Hooper, R. P. and Shoemaker, C. A.: A comparison of chemical and isotopic hydrograph separation, Water Resour. Res., 22, 14441454, 1986.

Hrachowitz, M., Soulsby, C., Tetzlaff, D., Dawson, J. J. C., Dunn, S. M., and Malcolm, I. A.: Using long-term data sets to understand transit times in contrasting headwater catchments, J. Hydrol., 367(3-4), 237-248, 2009.

Hrachowitz, M., Soulsby, C., Tetzlaff, D., Dawson, J. J. C., and Malcolm, I. A.: Regionalization of transit time estimates in montane catchments by integrating landscape controls, Water Resour. Res., 45, W05421, doi:10.1029/2008WR007496, 2009b.

Instituto Geográfico Agustín Codazzi - IGAC, Suelos Departamento del Quindío. CRQ, Armenia, 1996.

International Atomic Energy Agency - IAEA, A new device for monthly rainfall sampling for GNIP, Water and Environment Newsletter, 16, p. 5, 2002.

Jakeman, A. J. and Hornberger, G. M.: How much complexity is warranted in a rainfall-runoff model?. Water Resour. Res., 29(8), 2637-2649, 1993.

Johnson, M. S., Weiler, M., Couto, E. G., Riha, S. J., and Lehmann, $\mathrm{J}$.: Storm pulses of dissolved $\mathrm{CO}_{2}$ in a forested headwater Amazonian stream explored using hydrograph separation, Water Resour. Res., 43, W11201, doi:10.1029/2007WR006359, 2007.

Kendall, C. and McDonnell, J. J.: Isotope Tracers in Catchment Hydrology, Elsevier Sci., New York, 839 pp., 1998.

Kirchner J. W., Feng, X. H., and Neal, C.: Catchment-scale advection and dispersion as a mechanism for fractal scaling in stream tracer concentrations, J. Hydrol., 254(1-4), 82-101, 2001.

Laudon, H., Sjoblom, V., Buffam, I., Seibert, J., and Morth, M.: The role of catchment scale and landscape characteristics for runoff generation of boreal streams, J. Hydrol., 344, 198-209, 2007.

Maloszewski, P. and Zuber, A.: Determining the turnover time of groundwater systems with the aid of environmental tracers. 1. Models and their applicability, J. Hydrol., 57, 207-231, 1982.

McCartney, M. P., Neal, C., and Neal, M.: Use of deuterium to understand runoff generation in a headwater catchment containing a dambo, Hydrol. Earth Syst. Sci., 2, 65-76, doi:10.5194/hess-265-1998, 1998.

McDonnell, J., Rowe, L. K., and Stewart, M. K.: A combined tracer-hydrometric approach to assess the effect of catchment scale on water flow path, source and age, in Integrated Methods in Catchment Hydrology-Tracer, Remote Sensing, and New Hydrometric Techniques, edited by: Leibundgut, C., McDonnell, J., and Schultz, G., IAHS Publ., 258, 265-273, 1999.

McGuire, K. J., McDonnell, J. J., Weiler, M., Kendall, C., McGlynn, B.L., Welker, J.M. and Seibert, J.: The role of topography on catchment-scale water residence time, Water Resour. Res., 41, W05002, doi:10.1029/2004WR003657, 2005.

McGuire, K. J. and McDonnell, J. J.: A review and evaluation of catchment transit time and modeling, J. Hydrol., 330, 543-563, 2006.

McGuire, K., Weiler, M., and McDonnell, J. J.: Integrating tracer experiments with modeling to assess runoff processes and water transit times, Adv. Water Resour., 30, 824-837, 2007. 
Pinder, G. F. and Jones, J. F.: Determination of the ground-water component of peak discharge from the chemistry of total runoff, Water Resour. Res., 5(2), 438-445, 1969.

Roa-García, C.: Wetlands and water dynamics in small headwater catchments of the Andes, PhD Thesis, Institute for Resources, Environment and Sustainability, University of British Columbia, 2009.

Sherman, L. K.: Streamflow from rainfall by the unit-graph method, Eng. News Rec., 108, 501-505, 1932.

Sklash, M. G., Farvolden, R. N., and Fritz, P.: A conceptual model of watershed response to rainfall, developed through the use of oxygen-18 as a natural tracer, Can. J. Earth Sci., 13, 271-283, 1976.

Soulsby, C., Tetzlaff, D., and Hrachowitz, M.: Tracers and transit times: windows for viewing catchment scale storage?, Hydrol. Process., 23, 3503-3507, 2009.

Stewart, M. K., and McDonnell, J. J.: Modeling baseflow soil water residence times from Deuterium concentrations, Water Res. Res., 27(10), 2681-2693, 1991.

Unnikrishna, P. V., McDonnell, J. J., and Stewart, M. K.: Soil water isotopic residence time modelling, in Solute Modelling in Catchment Systems, edited by: Trudgill, S. T., 237-260, John Wiley, Hoboken, N. J., 1995.
Vaché, K. B. and McDonnell, J. J.: A process-based rejectionist framework for evaluating catchment runoff model structure, Water Resour. Res., 42, W02409, doi:10.1029/2005WR004247, 2006.

Vitvar, T., Aggarwal, P. K., and McDonnell, J. J.: A review of isotope applications in catchment hydrology, in Isotopes in the Water Cycle: Past, Present and Future of a Developing Science, edited by: Aggarwal, P. K., Gat, J. R., and Froehlich, K. F. O., 151-169, 2005.

Weiler, M., Scherrer, S., Naef, F., and Burlando, P.: Hydrograph separation of runoff components based on measuring hydraulic state variables, tracer experiments and weighting methods, IAHS Publ., 258, 249-255, 1999.

Weiler, M., McGlynn, B. L., McGuire, K. J., and McDonnell, J. J.: How does rainfall become runoff? A combined tracer and runoff transfer function approach, Water Resour. Res., 39, (11), 1315, doi:10.1029/2003WR002331, 2003. 